\title{
An Outbreak of Conjunctivitis Caused by Multiresistant Pseudomonas aeruginosa in a Brazilian Newborn Intensive Care Unit
}

\author{
D. V. D. Brito, E. J. Oliveira, C. Matos, V. O.S. Abdallah \\ and P.P. Gontijo Filho
}

\begin{abstract}
Institute of Biomedical Science, Clinical Hospital, Federal University of Uberlândia, Uberlândia, $M G$, Brazil
\end{abstract}

\begin{abstract}
We report an outbreak of conjunctivitis due to Pseudomonas aeruginosa involving seven infants admitted in the Neonatal Intensive Care Unit (NICU) of the Uberlândial Federal University Hospital between March and September 2001. Three infants developed systemic complications (01 sepsis and 02 pneumonias). Ten isolates were obtained from conjunctival cultures and all were resistant to ceftazidime and aminoglycosides. Fast identification of the organism and treatment with imipenem were important in containing the outbreak of $P$. aeruginosa. Key Words: Pseudomonas aeruginosa, nosocomial infection, neonatal unit.
\end{abstract}

Outbreaks of multiresistant Pseudomonas aeruginosa infection in Newborn Intensive Care Units (NICU) are often associated with high mortality rates [1]. Preterm infants are potentially at risk for infection with $P$. aeruginosa because they may be immunocompromised, they often require supplemental oxygen and/or mechanical ventilation, they may have indwelling intravenous catheters and they require prolonged hospitalization [2,3]. Pseudomonas. aeruginosa conjunctivitis during infancy may lead to a rapidly progressive, invasive eye infection. In some cases this destructive eye disease is associated with or followed by infection at other sites, but there have been cases of $P$. aeruginos $a$ conjunctivitis in hospitalized, premature infants who developed systemic complications without invasive eye infection [4,5].

We studied an outbreak of $P$. aeruginosa noninvasive conjunctivitis in infants in our NICU and examined risk factors and possible sources. Between March and September 2001 seven babies were found

Received on 20 February 2003; revised 19 May 2003.

Address for correspondence: Dr. Paulo Gontijo. Instituto de Ciências Biomédicas, Hospital de Clínicas Universidade Federal de Uberlândia, Uberlândia - MG, Brazil.

The Brazilian Journal of Infectious Diseases 2003;7(4):234-235 (C) 2003 by The Brazilian Journal of Infectious Diseases and Contexto Publishing. All rights reserved. to be infected with $P$. aeruginosa. Ten isolates obtained from conjunctival cultures were identified by the hospital microbiology laboratory. The index case occurred during the last week of March and there were several clinical problems: congenital malformations, coma and tracheostomy (Table1). One of the infants, who was born prematurely and weighed less than $1000 \mathrm{~g}$, subsequently developed a fulminating septicaemia, also provoked by $P$. aeruginosa; this patient died, but all the others recovered after treatment with imipenem and ciprofloxacin. All the infants were cared for in an incubator, were treated with antibiotics and had ventilator support. This epidemic strain of $P$. aeruginosa, which was resistant to ceftazidime and aminoglycosides, could have been disseminated by health care worker's hands or by aerosolization from endotracheal tube aspirates of the respiratory tract of neonates requiring prolonged endotracheal intubation and mechanical ventilation; the epidemic strain of $P$. aeruginosa was isolated from the respiratory tract of two infants (cases 1 and 6), and later, after infection was diagnosed in their eyes, developed pneumonia by clinical and radiological criteria.

Among these seven hospitalized infants with $P$. aeruginosa conjunctivitis, only three (1 sepsis and 2 pneumonias) developed systemic complications of $P$. aeruginosa infection; in the other four there was no 
Table 1. Clinical characteristics of seven infants infected with Pseudomonas aeruginosa during an outbreak of conjunctivitis in a Brazilian natal intensive care unit between March and September 2001

\begin{tabular}{|c|c|c|c|c|c|c|c|c|}
\hline Case & Infection & Diagnostic & $\begin{array}{l}\text { Invasive } \\
\text { procedures }\end{array}$ & Weight (g) & Incubator & $\begin{array}{l}\text { Ventilator } \\
\text { support }\end{array}$ & Antibiotics & Evolution \\
\hline $1^{\mathrm{a}}$ & $\begin{array}{l}\text { Conjunctivitis } \\
\text { and Pneumonia }\end{array}$ & Malformation & PVC & 3320 & + & + & + & Discharge \\
\hline 2 & Conjunctivitis & Malformation & PVC & 1280 & + & + & + & Discharge \\
\hline 3 & $\begin{array}{l}\text { Conjunctivitis } \\
\text { and Sepsis }\end{array}$ & $\begin{array}{l}\text { Respiratory } \\
\text { discomfort }\end{array}$ & PVC & 780 & + & + & + & Died \\
\hline 4 & Conjunctivitis & HMD & Intubation & 940 & + & + & + & Discharge \\
\hline 5 & Conjunctivitis & Coma & Intubation & 3240 & + & + & + & Discharge \\
\hline 6 & $\begin{array}{l}\text { Conjunctivitis } \\
\text { and Pneumonia }\end{array}$ & $\begin{array}{l}\text { Esophagus } \\
\text { atresia }\end{array}$ & $\begin{array}{l}\text { Thoracic } \\
\text { drain }\end{array}$ & 2270 & + & + & + & Discharge \\
\hline 7 & Conjunctivitis & $\begin{array}{l}\text { Esophagus } \\
\text { atresia }\end{array}$ & $\begin{array}{l}\text { Thoracic } \\
\text { drain }\end{array}$ & 2050 & + & + & + & Discharge \\
\hline
\end{tabular}

$\mathrm{a}=$ index case.

$\mathrm{PVC}=$ peripheral deep venous catheter $\mathrm{HMD}=$ hyaline membrane disease.

evidence of invasive eye disease, probably due to early detection and treatment with imipenem and ciprofloxacin eye drops.

\section{References}

1. Grundmann H., Kropec A., Harting D. Pseudomonas aeruginosa in a neonatal intensive care unit: reservoirs and etiology of the nosocomial pathogen. J Infect Dis 1993; $168: 943-7$.

2. Leigh L., Stoll B.J, Rahman M., McGowan Jr. J. Pseudomonas aeruginosa infection in very low birth weight infants: a case-control study. Pediatr Infect Dis J 1995; 14:367-71.

3. Slagle T.A., Bifano E.M., Wolf J.W., Gross S.J. Routine endotracheal cultures for the prediction of sepsis in ventilated babies. Arch Dis Child 1989;64:34-8.

4. King S., Devi S.P., Mindorff C., et al. Nosocomial Pseudomonas aeruginosa conjunctivitis in a pediatric hospital. Infect Control Hosp Epidemiol 1998;9:77-80.

5. Shah S.S., Gallagher P.G. Complications of conjunctivitis caused by Pseudomonas aeruginosa in a newborn intensive care unit. Pediatr Infect Dis J 1998; 17:97-102. 